\title{
Impact of Fluconazole versus Posaconazole Prophylaxis on the Incidence of Fungal Infections in Patients Receiving Induction Chemotherapy for Acute Myeloid Leukemia
}

\author{
Camille Devanlay ${ }^{1,2}$, Emmanuelle Tavernier-Tardy ${ }^{2}$, Aurélie Bourmaud ${ }^{3}$, Alexander Tuan Falk ${ }^{4}$, \\ Hélène Raberin ${ }^{5}$, Sandrine Menguy ${ }^{6}$, Denis Guyotat ${ }^{2}$, Nicolas Magné $^{7}$, Jérôme Cornillon ${ }^{2}$
}

Background: Invasive fungal infections (IFIs) remain one of the worrying complications in patients with acute myeloid leukemia (AML) due to their incidence and high level of attributable mortality. In light of these risks, antifungal prophylaxis has always been debated. We conducted a single-center retrospective study of two prophylactic antifungal agents (fluconazole/posaconazole) in 91 consecutive patients receiving induction chemotherapy for AML between 2005 and 2009, in order to evaluate the impact on the incidence of IFI and on the mycological flora of the patients.

Methods: In total, 39 patients received prophylactic fluconazole versus 52 who received posaconazole. The baseline characteristics of the two groups were comparable.

Results: $\quad$ Overall, 17 patients developed an IFI, with no difference in frequency between the two groups. Utilization of empirical or pre-emptive therapy was similar irrespective of the type of prophylaxis used. Mycological examination of stools revealed an increase in non-albicans Candida colonization in the fluconazole group during hospitalization and the appearance of Saccharomyces cerevisiae colonization in patients receiving posaconazole.

Conclusion: The present study does not distinguish between fluconazole and posaconazole as a primary effective prevention against fungal infections. More prospective studies and meta-analyses are warranted.

(Biomed J 2015;38:235-243)

\section{At a Glance Commentary}

Scientific background of the subject

In 2009, the ECIL has recommended larger spectrum prophylaxis using posaconazole in high-risk patients with acute myeloid leukemia or myelodysplastic syndrome receiving intensive chemotherapy. With the authorization to market posaconazole, our old prophylactic regimen using fluconazole was replaced with one using posaconazole. Evaluations of posaconazole treatments are needed to further gather data on this matter.

\section{What this study adds to the field}

Our protocols to empirically treat invasive fungal infection were modified to use posaconazole. We evaluated whether these changes of practice had an impact in terms of patient management. Our results found no difference between posaconazole and fluconazole in contrast with other recent studies.

\section{Key words: acute myeloid leukemia, antifungal prophylaxis, invasive fungal infections}

$\mathrm{F}$ ungal infections are related to human communal agents or to environmental saprophytes and are rare in healthy subjects. Known contributing factors are reduced defense mechanisms of the host, the use of certain

From the ${ }^{1}$ Département d'Oncologie Médicale, Institut de Cancérologie Lucien Neuwirth, France; ${ }^{2}$ Département d'Hématologie Clinique, Institut de Cancérologie Lucien Neuwirth, France; ${ }^{3}$ Département de Santé Publique, Institut de Cancérologie Lucien Neuwirth, France; ${ }^{4}$ Departement of Radiation Oncology, Centre Antoine Lacassagne, Nice, France; ${ }^{5}$ Laboratoire de Parasitologie-Mycologie, Centre Hospitalier Universitaire de St-Etienne, France; ${ }^{6}$ Pharmacie, Institut de Cancérologie Lucien Neuwirth, France; ${ }^{7}$ Département de Radiothérapie, Institut de Cancérologie Lucien Neuwirth, France

Received: Apr. 6, 2014; Accepted: Sep. 12, 2014

Correspondence to: Dr. Alexander Tuan Falk, Departement of Radiation Oncology, Centre Antoine Lacassagne, Nice, France. 33 Avenue valombrose, 06000 Nice, France. Tel: 33-49-2031000; Fax: 33-49-2031010; E-mail: alexander.falk.fr@gmail.com

DOI: $10.4103 / 2319-4170.143491$ 
treatments (chemotherapy, corticosteroids, large-spectrum antibiotics, parenteral feeding, etc.), foreign objects (notably blood and urinary catheters), as well as the presence of fungi in the environment (Aspergillus and work). ${ }^{[1,2]}$

In patients with hematological malignancies, the incidence of invasive fungal infections (IFIs) has increased regularly during the last decade. The majority of these infections occur in patients with acute myeloid leukemia or myelodysplastic syndrome (MDS) or in those who have received allogenic hematopoietic stem cell transplants. ${ }^{[3,4]}$ In patients with acute leukemia, the incidence of proven/probable IFI is estimated to be $24 \%$ (varying from 2 to $40 \%$ depending on the center). ${ }^{[5-7]}$ The predominant species involved in Europe are Candida sp. and Aspergillus sp. However, in patients with hematological malignancies, Aspergillus species are the most frequent causal agents. ${ }^{[8-10]}$ The mortality rate attributable to IFI is estimated to be between $6 \%$ and $60 \%$, depending on the type of infectious agent. Due to their frequency and severity, IFIs increase the duration of hospitalization and, hence, the hospitalization costs. In light of the consequences in these high-risk patients, large-spectrum prophylaxis is often recommended. ${ }^{[11,12]}$ In addition, it is actually admitted that the delay in instituting an adequate therapy is a negative factor in terms of mortality. Due to this, empiric therapy is frequently instituted in view of the slightest clinical suspicion. ${ }^{[13,14]}$ The principal consequence of this practice is the difficulty in identifying the causal agent in more than $50 \%$ of fungal infections due to negative cultures ${ }^{[15,16]}$ as well as the emergence of resistant fungi (non-albicans Candida, Aspergillus flavus or terreus, Fusarium sp., and Zygomycetes sp.). ${ }^{[17-22]} \mathrm{Fi}-$ nally, pre-emptive therapy, targeting Aspergillus, would limit the over-treatment of the patients, thereby reducing the emergence of resistance, debilitating side effects, and costs. However, this approach is not yet the standard of care. ${ }^{[23-26]}$

In 2007, the European Conference on Infections in Leukemia patients (ECIL) proposed molecules such as fluconazole or itraconazole as preventive antifungals, for which the major drawbacks are the absence of efficacy for Aspergillus sp. and/or intolerance. ${ }^{[27,28]}$ In 2009, the ECIL has recommended larger spectrum prophylaxis using posaconazole in high-risk patients with AML or MDS receiving intensive chemotherapy.

With the authorization to market posaconazole, our old prophylactic regimen using fluconazole was replaced with one using posaconazole. Our protocols to empirically treat IFI were also modified. We, therefore, wanted to evaluate whether these changes of practice had an impact in terms of patient management.

\section{METHODS}

\section{Patients}

The population included in this study consisted of patients aged 18 years and older, with a primary diagnosis of AML or MDS, who were hospitalized in our unit between 2005 and 2009 for induction chemotherapy to produce prolonged neutropenia ( $>10$ days) and who received prophylactic fluconazole or posaconazole against IFI.

\section{Study outline}

This is a retrospective, pre-post comparative study involving 91 consecutive patients. During the first period of the study (2005-2007), all patients $(n=39)$ received prophylactic antifungal therapy consisting of fluconazole $400 \mathrm{mg}$ p.o., with or without a non-absorbable gut decontamination, beginning on the first day of the induction chemotherapy. All patients received an induction treatment sequence based on anthracycline (idarubicine for the majority of patients) and aracytine intravenously continuously during $24 \mathrm{~h}$. Dose and duration were fixed according to age (notably in the case of age up to 60 years). During the second period of the study (2007-2009), all patients $(n=52)$ received prophylactic antifungal therapy consisting of posaconazole $200 \mathrm{mg}$ p.o. t.i.d., with or without a non-absorbable gut decontamination, beginning on the first day of the induction chemotherapy. The first febrile episode was treated with a broad-spectrum antibiotic as monotherapy after investigation of the causative agent. The persistence of fever after $72 \mathrm{~h}$ or the occurrence of a new febrile episode, non-documented, at more than $72 \mathrm{~h}$ after initiation of the antibiotic therapy resulted in the initiation of an empirical antifungal therapy consisting of caspofungin for the fluconazole group and liposomal amphotericin B $(3 \mathrm{mg} / \mathrm{kg} / \mathrm{day})$ for the posaconazole group.

During the two study periods, all patients (except two) were lodged in individual rooms equipped with HEPA particle filters and positive pressure. All patients received vacuum-conditioned food. They underwent mycological follow-up during their stay, which consisted of direct examination and culture of buccal lavage and a daily sampling of stools. The search for antigens and serology for Aspergillus were performed twice weekly. The same examinations were conducted upon the readmission of each patient during follow-up treatment.

Suspicion of clinical or radiological pneumonia or a positive Aspergillus antigen test resulted in a computed tomography (CT) scan and a change in the prophylactic or empiric antifungal therapy to pre-emptive therapy with voriconazole ( $400 \mathrm{mg}$ b.i.d. i.v. for $48 \mathrm{~h}$ followed by $200 \mathrm{mg}$ 
b.i.d. p.o.). ${ }^{[29,30]}$ Depending on the pulmonary condition and the patient's clinical status, a broncho-alveolar lavage (BAL) was performed for bacteriological and mycological testing.

This retrospective non-interventional observational study obtained confidential approval from the Commission nationale de l'informatique et des libertés (CNIL). Local ethics board approval was obtained for the analysis of patient data. Helsinki convention criteria were respected for the purposes of the present study. Informed consent of patients was not required as data were anonymized.

\section{Definitions}

Severe neutropenia was defined as a polynuclear neutrophil count of $<0.5 \mathrm{~g} / \mathrm{l}$. The karyotype was classified into three categories as good, intermediate, or poor prognosis, according to the classification of Grimwade. ${ }^{[31]}$ IFIs were defined as proven, probable, or possible in conformity with the European Organization for Research and Treatment of Cancer (EORTC) criteria. ${ }^{[32]}$ The galactomannan test was designated positive at a value $>0.5 .^{[33]}$

\section{Cost analysis}

The study took into account the hospital costs related to the prophylactic, empirical, and pre-emptive therapy for IFI. The costs used for the years before 2009 were actualized according to the annual index of hospital costs. Specifically for fluconazole, which became generic between 2007 and 2008 , the price actualization was approached differently in order to respect the between-group comparison. The other associated costs were ignored under the hypothesis that the duration of hospitalization, nursing costs, and the cost of concomitant treatments should have been equivalent for the two groups. The unit costs (per day) for the antifungals for each year were taken from the hospital pharmacy for all the drugs used. ${ }^{[34]}$

\section{Outcome criteria}

The principal outcome criterion was the incidence of proven or probable fungal infections recorded at the end of the neutropenia induced by the chemotherapy. Secondary criteria included the number of possible IFIs, the duration of prophylactic and empirical therapy, the incidence of associated bacterial infections, the evolution of the mycological flora of the patients, as well as the effect of prophylaxis on colonization. The costs of the antifungal therapies were also evaluated.

\section{Statistical analysis}

The statistical analysis was conducted using $\mathrm{SAS}^{\circledR}$, version 9.2 software. A univariate analysis was performed for all the variables which could have been affected by prophylactic treatment, and the comparisons were carried out using the Chi-squared or the Fisher's test for qualitative variables and the Wilcoxon-Mann-Whitney test for quantitative variables. All patients were followed up to the end date of the study (31 July 2010) or until death if it occurred prior to the end date of the study. Global survival was estimated using the Kaplan-Meier method, and the stratified curves for prophylaxis and the IFIs were analyzed using the log-rank test. Finally, a multivariate analysis was performed using the Cox model.

\section{RESULTS}

\section{General characteristics of the population}

The general characteristics of the population are given in Table 1. In total, 91 patients received prophylactic therapy. Thirty-nine (43\%) received fluconazole and $52(57 \%)$ received posaconazole. The mean age was 56 years (range 23-80 years). The principal demographic variables were similar for the two groups in terms of sex, medical history, type of pathology, presence of hyperleukocytosis at diagnosis (30\% of patients), and neuro-meningeal invasion ( $4 \%$ of patients). The presence of neutropenia at admission was more frequent in the fluconazole group (44\% vs $29 \%, p=\mathrm{NS})$. Hospitalization prior to admission to the isolation unit occurred in 25 patients $(48 \%)$ in the posaconazole group versus 10 patients $(26 \%)$ for the fluconazole group $(p=0.03)$. Two-thirds of the cases arrived from the emergency unit.

Overall, $89 \%$ of patients were in complete remission at the end of therapy, with $15 \%$ requiring remedial chemotherapy on Day 15. The mean duration of neutropenia was 28.7 days (range $8-81$ days) for fluconazole patients and 32.2 days (range 12-182 days) for those receiving posaconazole $(p=\mathrm{NS})$.

\section{Infectious characteristics of the population}

Infectious characteristics of the population are presented in Table 2. During hospitalization, each patient received between 0 and five different antibiotics, with a mean of 2.8 antibiotics per patient in the fluconazole group and 2.6 antibiotics per patient in the posaconazole group ( $p=\mathrm{NS})$. The average duration of prophylaxis was 14.4 days, which was comparable between the two groups. Thereafter, $80 \%$ patients received an empirical antifungal therapy consisting of caspofungin for 32 patients $(82 \%)$ receiving fluconazole and liposomal amphotericin B for 39 posaconazole patients $(75 \%)$. The primary cause for instituting empirical treatment was a new febrile episode. Only five fluconazole patients and nine posaconazole patients received just the prophylactic treatment. Concerning the pre-emptive therapy 
for invasive pulmonary aspergillosis (IPA), 35\% $(n=32)$ of patients received voriconazole.

Forty-two pulmonary CT scans were performed in 37 patients, and $29 \%$ were compatible with a diagnosis of IPA. The second CT scan performed for five patients permitted the readjustment of the diagnosis from non-specific pneumonia to probable IPA in two cases. Six fluconazole patients and seven posaconazole patients received a bronchial fibros-

Table 1: General characteristics of the population

\begin{tabular}{|c|c|c|c|}
\hline & $\begin{array}{l}\text { Fluconazole } \\
\qquad(n=39)\end{array}$ & $\begin{array}{l}\text { Posaconazole } \\
\quad(n=52)\end{array}$ & $p$ \\
\hline Age (years) & $56.1(29-80)$ & $56.2(23-75)$ & 0.98 \\
\hline \multicolumn{4}{|l|}{ Sex } \\
\hline Male & $26(66.7)$ & $31(59.6)$ & \multirow[t]{2}{*}{0.49} \\
\hline Female & $13(33.3)$ & $21(40.4)$ & \\
\hline \multicolumn{4}{|l|}{ Medical history } \\
\hline Diabetes & $4(10.3)$ & $5(9.6)$ & 1.00 \\
\hline Cardiac insufficiency & $2(5.1)$ & $1(1.9)$ & 0.57 \\
\hline Arrhythmia & $0(0.0)$ & $3(5.8)$ & 0.26 \\
\hline VA-TIA & $0(0.0)$ & $1(1.9)$ & 1.00 \\
\hline Previous psychiatric disease & $3(7.7)$ & $4(7,7)$ & 1.00 \\
\hline $\mathrm{BMI}>35$ & $1(2.6)$ & $1(1.9)$ & 1.00 \\
\hline Renal Insufficiency & $1(2.6)$ & $0(0.0)$ & NA \\
\hline COPD & $2(5.1)$ & $2(3.9)$ & 1.00 \\
\hline Previous cancer & $2(5.1)$ & $4(7.7)$ & 0.70 \\
\hline Previous hematological disease & $4(10.3)$ & $2(3.9)$ & 0.40 \\
\hline \multicolumn{4}{|l|}{ Pathology } \\
\hline AML & $37(94.9)$ & $46(88.5)$ & \multirow[t]{2}{*}{0.50} \\
\hline MDS & $2(5.1)$ & $6(11.5)$ & \\
\hline AML-t & $7(18.0)$ & $3(5.8)$ & 0.09 \\
\hline Neutropenia at entry & $17(43.6)$ & $15(28.9)$ & 0.14 \\
\hline Neurological involvement & $3(7.7)$ & $0(0.0)$ & 0.08 \\
\hline Hyperleukocytosis & $11(28.2)$ & $14(26.9)$ & 0.89 \\
\hline \multicolumn{4}{|l|}{ Karyotype } \\
\hline Good prognosis & $6(15.4)$ & $14(27.5)$ & \multirow[t]{3}{*}{0.15} \\
\hline Intermediate prognosis & $17(43.6)$ & $25(49.0)$ & \\
\hline Poor prognosis & $16(41.0)$ & $12(23.5)$ & \\
\hline Complete remission obtained & $35(89.7)$ & $46(88.5)$ & 1.00 \\
\hline Remedial at D15 & $8(20.5)$ & $6(11.5)$ & 0.24 \\
\hline Remedial at D40 & $1(2.6)$ & $2(3.9)$ & 1.00 \\
\hline Allo-transplant & $16(41.0)$ & $23(45.1)$ & 0.70 \\
\hline Neutropenia duration $\mathrm{PNN}<0.5$ & $28.7(8-81)$ & $32.2(12-182)$ & 0.42 \\
\hline Neutropenia duration $\mathrm{PNN}<0.1$ & $19.8(4-49)$ & $23.3(9-76)$ & 0.16 \\
\hline \multicolumn{4}{|l|}{ Cause of death } \\
\hline Infection & $3(11.5)$ & $3(12.5)$ & \multirow[t]{5}{*}{ NA } \\
\hline Relapse & $13(50.0)$ & $11(45.8)$ & \\
\hline Toxicity & $5(19.2)$ & $8(33.3)$ & \\
\hline GVH & $2(7.7)$ & $1(4.2)$ & \\
\hline Other & $3(11.5)$ & $1(4.2)$ & \\
\hline \multicolumn{4}{|l|}{$\begin{array}{l}\text { Hospitalization prior to unit } \\
\text { admission }\end{array}$} \\
\hline Yes & $10(25.6)$ & $25(48.1)$ & 0.03 \\
\hline
\end{tabular}

Abbreviations: NA: Not applicable; BMI: Body mass index; AML: Acute myeloid leukemia; MDS: Myelodysplastic syndrome
Table 2: Infectious characteristics of the population

\begin{tabular}{|c|c|c|c|}
\hline & $\begin{array}{c}\text { Fluconazole } \\
\qquad(n=39)\end{array}$ & $\begin{array}{c}\text { Posaconazole } \\
\quad(n=52)\end{array}$ & $p$ \\
\hline Duration of prophylaxis & $14.2(2-41)$ & $14,8(3-42)$ & 0.74 \\
\hline Gut decontamination & $25(64,1)$ & $7(13.5)$ & $<0,0001$ \\
\hline Delay for fever (days) & $5.1(0-14)$ & $4.5(0-19)$ & 0.60 \\
\hline ATB empiric & $39(100.0)$ & $51(98.1)$ & 1.00 \\
\hline \multicolumn{4}{|l|}{ ATB received } \\
\hline Imipenem & $37(94.9)$ & $2(3.9)$ & $<0.0001$ \\
\hline Piperacilline-tazo & $2(5.1)$ & $49(96.1)$ & \\
\hline Bi-therapy & $6(15.4)$ & $9(17.1)$ & 0.81 \\
\hline $\mathrm{Nb}$ of ATB received & $2.8(1-5)$ & $2,6(0-5)$ & 0.38 \\
\hline \multicolumn{4}{|l|}{$\mathrm{Nb}$ documented infections } \\
\hline Bacteremia & $14(34.2)$ & $10(19.2)$ & 0.10 \\
\hline Pneumonia & $5(12.8)$ & $10(19.2)$ & 0.41 \\
\hline Infection urinary & $1(2.6)$ & $8(15.4)$ & 0.07 \\
\hline Sinusitis & $1(2.6)$ & $0(0.0)$ & 0.43 \\
\hline Infection skin & $3(7.7)$ & $9(17.0)$ & 0.19 \\
\hline Other & $8(20.0)$ & $3(5.8)$ & 0.05 \\
\hline No documentation & $16(41.0)$ & $22(42.3)$ & 1.00 \\
\hline No infection & $0(0.0)$ & $2(3.9)$ & 0.50 \\
\hline $\mathrm{Nb}$ documented infections/patient & $0.82(0-3)$ & $0.77(0-3)$ & 0.76 \\
\hline \multicolumn{4}{|l|}{ Microbe identified } \\
\hline GNB & $3(7.5)$ & $9(16.7)$ & 0.23 \\
\hline MRSA & $0(0.0)$ & $1(1.9)$ & 1.00 \\
\hline MSSA & $2(5.1)$ & $1(1.9)$ & 0.57 \\
\hline S. coagulase negative & $11(28.2)$ & $10(19.2)$ & 0.31 \\
\hline Other cocci & $4(10.3)$ & $3(5.8)$ & 0.46 \\
\hline Other & $6(15.4)$ & $0(0.0)$ & 0.01 \\
\hline AFE & $33(84.6)$ & $40(76.9)$ & 0.36 \\
\hline \multicolumn{4}{|l|}{ AFE } \\
\hline Caspofungin & $32(82.1)$ & $1(1.9)$ & $<0.0001$ \\
\hline Liposomal amphotericin B & $1(2.6)$ & $39(75.0)$ & \\
\hline None & $6(15.4)$ & $12(23.1)$ & \\
\hline Delay return of fever & $8.1(3-29)$ & $9,3(2-34)$ & 0.46 \\
\hline Duration of AFE & $14.8(2-49)$ & $14.6(1-43)$ & 0.92 \\
\hline Patients treated with voriconazole & $15(38.5)$ & $17(32.7)$ & 0.57 \\
\hline Delay in return of fever & $23.0(10-40)$ & $17.8(3-51)$ & 0.24 \\
\hline Pulmonary CT & $19(48.7)$ & $23(44.2)$ & 0.67 \\
\hline \multicolumn{4}{|l|}{ Results } \\
\hline Negative & $5(26.3)$ & $8(34.8)$ & 0.55 \\
\hline Non-specific & $7(36.8)$ & $10(43.5)$ & \\
\hline Compatible IPA & $7(36.8)$ & $5(21.7)$ & \\
\hline Fibroscopy BAL & $6(15.4)$ & $7(13.5)$ & 0.80 \\
\hline \multicolumn{4}{|l|}{ IFI } \\
\hline IFI proven/probable & $6(66.7)$ & $5(62.5)$ & 1.00 \\
\hline IFI possible & $3(33.3)$ & $3(37.5)$ & \\
\hline \multicolumn{4}{|l|}{ Type IFI } \\
\hline Candidosis & $2(5.1)$ & $0(0.0)$ & 0.18 \\
\hline Aspergillosis & $7(18.0)$ & $8(15.4)$ & 0.74 \\
\hline \multicolumn{4}{|l|}{ Aspergillosis } \\
\hline Proven/probable & $4(57.1)$ & $5(62.5)$ & 1.00 \\
\hline Possible & $3(42.9)$ & $3(37.5)$ & \\
\hline
\end{tabular}

Abbreviations: NA: Not Applicable; CT: Computed tomography; IPA: Invasive pulmonary aspergillosis; BAL: Broncho-alveolar lavage; IFI: Invasive fungal infection 
copy with BAL. These examinations added further support to suspicion of a fungal infection in three cases (two examinations were positive for filaments and onebronchoalveolar lavage fluid was very positive upon antigen testing), but these three cases were already classified as probable IPA prior to BAL. Eighteen percent of patients $(n=16)$ had a positive Aspergillus antigen test during their hospitalization. The delay to positive tests was 19.8 days in the posaconazole group versus 14.9 days in the fluconazole group ( $p=\mathrm{NS}$ ). Of the patients with positive antigen results, serology for Aspergillus was positive in only $25 \%$ of the cases.

\section{Fungal infection characteristics}

Proven or probable IFI was found in $11(12 \%)$ of the patients. Taking into account the possible IFIs, the number was 17 (19\%), with the difference between the two groups being non-significant. In the fluconazole group, two candidemias were identified (one due to Candida glabrata and the other one due to Candida krusei). Histological evidence of the three cases identified as IPA was obtained a posteriori (one cerebral biopsy and one pulmonary biopsy positive for filaments with species identification, and one cutaneous biopsy positive for Aspergillus terreus). Thirty-six percent of the patients who received remedial chemotherapy on Day 15 developed an IPA (proven, probable, or possible) versus $13 \%(n=11)$ of patients who did not receive additional chemotherapy on Day $15(p=0.05)$. Furthermore, 9 out of 19 patients (47\%) who had a poor karyotype prognosis developed an IPA versus 2 out of 18 with a good prognosis and 4 out of 39 with an intermediate prognosis $(p=0.027)$.

\section{Survival outcomes}

Global survival at 3 years was estimated to be $35 \%$. The median survival time for patients without IFI was 27.6 months versus 12 months for patients with an IFI $(p=0.07)$ [Figure 1A]. No difference in survival as a function of the prophylaxis type used was identified [Figure 1B]. Causes of death were similar in the two groups, with $49 \%(n=25)$ of deaths related to disease relapse. No death was directly imputable to IFI. In the univariate analysis, the estimated risk of death in the presence of an IFI was 1.8 [95\% confidence interval (CI): 0.9-3.6]. However, in the multivariate analysis, the only significant

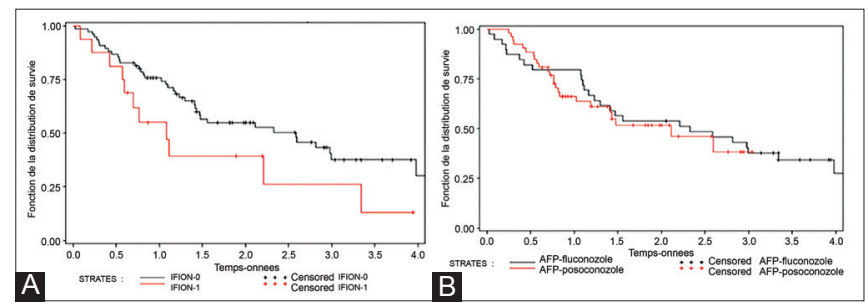

Figure 1: (A) Global survival curve stratified by IFI; (B) global survival curve stratified by prophylaxis type factors identified were the karyotypes of poor prognosis and intermediate prognosis [Tables 3 and 4]. Of note, two deaths were reported before the $28^{\text {th }}$ day, both under fluconazole and due to toxicity, in the first 100 days.

\section{Mycological colonization}

\section{Buccal swaps}

Compared to the posaconazole group, we noted a larger proportion of patients colonized with non-albicans Candida at study entry in the fluconazole group, a difference which widened at study exit (15\% vs $21 \%$ for fluconazole; $6 \%$ vs $4 \%$ for posaconazole). Half of the non-albicans Candida isolates were identified as $C$. glabrata. At consolidation, all samples were negative in the posaconazole group as compared with only $77 \%(n=14)$ in the fluconazole group $(p=0.016)$.

\section{Stool cultures}

The microbial types identified in stool cultures are shown in Figure 2A and B. The number of positive cultures in the two groups was identical at study entry [15 positive samples in the fluconazole group vs 14 in the posaconazole group $(p=0.17)]$ and study exit [19 vs 20 samples $(p=0.22)$ ] [Table 5]. The number of positive samples at entry $(n=29)$ and exit $(n=39)$ was statistically different $(p=0.003)$. The percentage of non-albicans Can-

Table 3: Univariate analysis of factors influencing global survival

\begin{tabular}{lcc}
\hline Univariate analysis & \multicolumn{2}{c}{ OS } \\
\cline { 2 - 3 } & HR $(95 \% \mathrm{CI})$ & $p$ \\
\hline Hyperleukocytosis & $1.13(0.6-2.09)$ & 0.7 \\
Karyotype & & \\
$\quad$ Poor prognosis & $7.7(2.2-25.9)$ & 0.001 \\
$\quad$ Intermediate & $4.9(1.4-16.3)$ & 0.008 \\
Remedial at D15 & $1.6(0.8-3.4)$ & 0.2 \\
Allo-transplant & $0.9(0.5-1.7)$ & 0.9 \\
Empirical ATB & $0.9(0.5-1.7)$ & 0.8 \\
PPI & $0.9(0.5-1.6)$ & 0.7 \\
Presence of IFI & $1.8(0.9-3.6)$ & 0.07
\end{tabular}

Abbreviations: OS: Overall survival; HR: Hazard ratio; CI: Confidence interval; ATB: Antibiotics; PPI: Proton pomp inhibitor; IFI: Invasive fungal infection

Table 4: Multivariate analysis

\begin{tabular}{lcc}
\hline Multivariate analysis & \multicolumn{2}{c}{ OS } \\
\cline { 2 - 3 } & HR $(95 \% \mathrm{CI})$ & $p$ \\
\hline Karyotype & $6.7(1.9-23.7)$ & 0.003 \\
Poor prognosis & $4.9(1.5-16.5)$ & 0.009 \\
$\quad$ Intermediate & $1.2(0.5-3)$ & 0.7 \\
Presence of IFI & Abbreviations: OS: Overall survival; HR: Hazard ratio; CI: Confidence \\
interval; IFI: Invasive fungal infection
\end{tabular}

Biomed J Vol. 38 No. 3 May - June 2015 
Table 5: Cross table of microbes pre-post, fluconazole versus posaconazole

\begin{tabular}{|c|c|c|c|c|c|c|c|}
\hline & \multicolumn{7}{|c|}{ Post sortie } \\
\hline & $\mathrm{AL}$ & NA & C. albicans & C. glabrata & C. krusei & Negative & Total \\
\hline \multicolumn{8}{|l|}{ Fluconazole } \\
\hline \multicolumn{8}{|l|}{ Pre } \\
\hline Other yeast & 0 & 0 & 0 & 0 & 0 & 1 & 1 \\
\hline C. albicans & 0 & 1 & 3 & 3 & 1 & 1 & 9 \\
\hline C. glabrata & 0 & 0 & 1 & 2 & 0 & 1 & 4 \\
\hline C. krusei & 0 & 0 & 0 & 0 & 1 & 0 & 1 \\
\hline Negative & 0 & 2 & 5 & 0 & 0 & 17 & 24 \\
\hline Total & 0 & 3 & 9 & 5 & 2 & 20 & 39 \\
\hline \multicolumn{8}{|l|}{ Posaconazole } \\
\hline \multicolumn{8}{|l|}{ Pre } \\
\hline Other yeast & 0 & 0 & 0 & 0 & 0 & 1 & 1 \\
\hline Other NA & 0 & 0 & 0 & 0 & 0 & 1 & 1 \\
\hline C. albicans & 1 & 0 & 4 & 0 & 0 & 5 & 10 \\
\hline C. glabrata & 0 & 0 & 0 & 2 & 0 & 0 & 2 \\
\hline Negative & 5 & 0 & 8 & 0 & 0 & 25 & 38 \\
\hline Total & 6 & 0 & 12 & 2 & 0 & 32 & 52 \\
\hline
\end{tabular}

Abbreviations: NA: Not applicable; AL: Applicable

dida progressed between entry and exit, increasing from $13 \%(n=5)$ to $24 \%(n=10)$. In the posaconazole group, $77 \%$ of samples $(n=38)$ were negative versus $67 \%(n=32)$ at study exit. Six colonizations with Saccharomyces cerevisiae were observed during hospitalization. Finally, at consolidation, $33 \%$ of the positive samples in the fluconazole group were C. glabrata and $50 \%$ of the positive samples in the posaconazole group were $S$. cerevisiae. Two C. glabrata (one in each group) had modified their sensitivity to fluconazole at study exit and maintained this change at consolidation.

\section{Cost analysis}

The average estimated actualized cost of antifungal therapy during hospitalization was 8973 Euros per patient in the fluconazole group (interval: 342.4-25,348.9€) and 10,062 Euros per patient in the posaconzole group (interval: $1196.5-35,715.9 €)(p=0.47)$. The average cost for empirical therapy was $8395.81 €$ for the fluconazole group versus 8563.89 for the posaconazole group $(p=\mathrm{NA})$.

\section{DISCUSSION}

Until 2007, fluconazole prophylaxis was the treatment of reference for the prevention of IFI in patients receiving hematopoietic stem cell transplantations. This prophylaxis was also often used in other high-risk patients, such as patients with AML receiving induction chemotherapy, even though there was little evidence that the use had an impact on their survival. ${ }^{[35]}$ The study by Cornely et al. led to a change in our practice with the label change for posaconazole for use in these patients. The Cornely

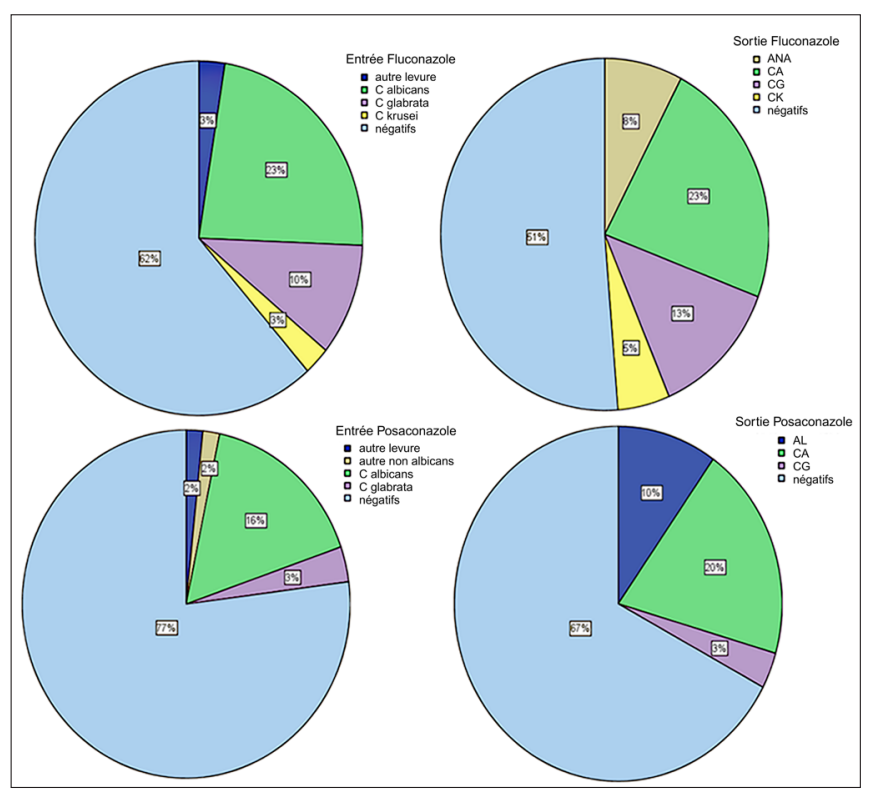

Figure 2: (A) Microbe type in stools pre-post in fluconazole group; (B) microbe type in stools pre-post in posaconazole group

study demonstrated the superiority of posaconazole over fluconazole and itraconazole in terms of the incidence of IFI ( $2 \%$ vs $8 \%$ ), with an impact on survival. ${ }^{[7]}$ Despite the homogeneity of our two groups, we did not detect the same difference.

In our study, the incidence of IFI appears to be relatively elevated (12\%), notably in the posaconazole group, even though none of the known classic supplementary risks were identified. Despite the availability of modern tools, the diagnosis remains difficult. In order to identify IPA, CT scan should be done when there is the slightest suspicion and should be repeated at regular intervals. The non-specific signs could be compatible with pulmonary aspergillosis and can lead to the diagnosis of possible IPA. The interpretation of CT scans by radiologists sensitized and oriented toward the possibility of aspergillosis could potentially increase the number of possible IPA cases because of the bias. A re-reading of the scans in concert with other members of the team could reduce the risk of this error. BAL is usually performed when the CT scan is abnormal, even in the absence of further suspicion. In our study, the use of BAL did not lead to a change in diagnosis. All the additional mycological evidence was obtained in patients already having a diagnosis of probable IPA due to the presence of host and mycological factors coupled with a compatible CT scan. Even though bronchofiberscopy with BAL can be performed in the majority of patients, it would probably be prudent to limit the procedure to patients with positive radiological signs but with a negative serum antigen result, in which case the BAL analysis could change the diagnosis of an infection from possible to probable. However, the test kit 
for the antigen is only validated for serum, and even though a positive result is one of the diagnostic criteria for probable IA (EORTC), no cutoff value has been defined to date. ${ }^{[33]}$ It should be noted, however, that the test can be considered reproducible within the same center. ${ }^{[36,37]}$ The analysis by serum polymerase chain reaction (PCR) in not yet standardized, particularly due to problems with contamination of the material collected. It is not yet part of the diagnostic criteria in actual use. ${ }^{[38]}$ Yet, certain centers use real-time PCR twice per week and begin antifungal therapy as soon as two consecutive positive results are obtained. ${ }^{[39]}$ The working group of the International Society for Human and Animal Mycology is preparing to propose a harmonization of protocols at the European level [European Aspergillus PCR initiative (EAPCRI)]. ${ }^{[40-42]}$ Finally, the evaluation of the serum $\beta$-glucan (present in fungal membranes) could be of global interest, but no evaluation in patients receiving prophylaxis is available. ${ }^{[43]}$

The absence of difference between the two groups in our study could eventually be explained by the limited sample size. However, there are a number of factors which could influence the metabolism of posaconazole, such as the pharmaceutical interactions or the occasional malabsorption resulting in reduced serum levels. In fact, there are a number of factors favoring the absorption of the molecule (such as a diet rich in fat, liquids with an acidic $\mathrm{pH}$ ) or limiting its absorption (such as the use of proton-pump inhibitor or metoclopramide, often utilized as an anti-emetic in patients receiving chemotherapy). ${ }^{[4,45]}$ The dose of posaconazole is recommended to reduce this risk. ${ }^{[46]}$ It should be noted that the duration of prophylaxis in this study was relatively short (14 days) in comparison with the Cornely study ${ }^{[7]}$ This difference is directly related to the rapid change in antifungal toward "empirical" therapy in the case of persistent fever or the occurrence of a new febrile episode. In light of the relatively high incidence of proven/probable IFIs, the value of using empirical therapy can be questioned. In effect, $88 \%$ of patients who received voriconazole received prior empirical therapy resulting in three changes of antifungal therapy used during the same hospitalization. In previous studies, empirical and pre-emptive therapies were evaluated without taking into account initial prophylactic therapy, if it was administered. In the Cornely study which evaluated prophylaxis, only $25 \%$ of patients required an additional systemic antifungal and then only in of IFI suspicion. Based upon these results, Stam et al. developed a predictive model of the average costs of the procedure and ascertained that prophylaxis with posaconazole appeared to be less expensive than with fluconazoleif the reduced incidence of IFI was taken into account. ${ }^{[47]}$ With this in mind, our focus reverts to the other hospitalization costs since no difference was noted between the two groups in terms of prophylaxis cost. This appears to be directly related to the high cost of empirical treatment.

The occurrence of an invasive fungal infection has been described as an independent risk factor for high mortality. ${ }^{[48]}$ No death was attributable to an IFI in this study. We did not note a significant difference with a $p$ value of 0.7 . However, this result may have been modulated by the strong impact that the karyotype had in the multivariate analysis and by the restricted sample size. On the other hand, no difference was seen as a function of the type of antifungal protocol used. For risk factors, the influence of remedial chemotherapy on Day 15 was noted, as close to $36 \%$ of these patients presented an IFI, as was the influence of a poor prognosis karyotype. It is important to foresee in these populations at high risk for aspergillosis an improvement in earlier diagnosis. It could be discussed whether systematic and regular pulmonary imaging needs to be done from Day 15 . Finally, the EORTC actually recommends couple imaging of the sinuses with a pulmonary CT scan in order to detect other locations of invasive aspergillosis, notably in patients having both host and mycological criteria. ${ }^{[32]}$

In the Cornely study, buccal and stool samples were analyzed once per week. In the two study arms, a decreased incidence of colonization was reported and no selection of species with a decreased sensitivity to azoles was detected. In our study, a significantly increased incidence of stool colonization by non-albicans Candida was noted between study entry and exit in patients receiving prophylactic fluconazole, suggesting a selection pressure for this type of prophylaxis. ${ }^{[17-21,49]} \mathrm{Con}-$ versely, in the posaconazole group, a significantly increased incidence of $S$. cerevisiae was observed at study exit. As far as is known, this emergence is not classically described for this population. ${ }^{[50]}$ It is of interest to note that this "selection pressure" was maintained over time as suggested by the positive results obtained on subsequent hospitalizations, on average 3 weeks later, implying an increased vigilance for the remainder of the patient management.

This study has shortcomings due to its retrospective nature and limited number of patients. Stool and buccal swab cultures have not been validated to assess colonization and efficacy of antifungal therapy; however, they are commonly used in this setting. ${ }^{[5]}$ The retrospective character made collection of data difficult, especially for side effects. We did not observe major toxicities, but it could be explained that patients presenting serious complications were hospitalized in different wards, explaining the absence of data. Our IFI incidence was high, making comparison to other historical series difficult with incidence ranging from $7 \%{ }^{[52]}$ with fluconazole prophylaxis to $21 \%$ in the absence of prophylaxis. ${ }^{[53]}$ We did not find objective explication for this difference; it could be explained by hygiene, regional and socio-economic disparities. An explanation could be that patients enrolled in this study were likely from a rural region. 


\section{Conclusion}

The present study does not distinguish any differencebetween fluconazole and posaconazole as a primary effective prevention against fungal infections. Nevertheless, one could observe an improvement in sensitivity in the group of patients treated with fluconazole, generating a careful approach. More prospective studies and meta-analyses are warranted.

\section{Acknowledgment}

The authors wish to thank Sally and Bill Miller, and Jenny Wilson for editing this manuscript.

\section{REFERENCES}

1. Barnes PD, Marr KA. Risks, diagnosis and outcomes of invasive fungal infections in haematopoietic stem cell transplant recipients. Br J Haematol 2007;139:519-31.

2. Blijlevens NM, Donnelly JP, de Pauw BE. Impaired gut function as risk factor for invasive candidiasis in neutropenic patients. Br J Haematol 2002;117:259-64.

3. Pagano L, Caira M, Candoni A, Offidani M, Fianchi L, Martino B, et al. The epidemiology of fungal infections in patients with hematologic malignancies: The SEIFEM-2004 study. Haematologica 2006;91:1068-75

4. Pagano L, Caira M, Valentini CG, Posteraro B, Fianchi L. Current therapeutic approaches to fungal infections in immunocompromised hematological patients. Blood Rev 2010;24:51-61.

5. Rotstein C, Bow EJ, Laverdiere M, Ioannou S, Carr D, Moghaddam N. Randomized placebo-controlled trial of fluconazole prophylaxis for neutropenic cancer patients: Benefit based on purpose and intensity of cytotoxic therapy. The Canadian Fluconazole Prophylaxis Study Group. Clin Infect Dis 1999;28:331-40.

6. Winston DJ, Chandrasekar PH, Lazarus HM, Goodman JL, Silber JL, Horowitz H, et al. Fluconazole prophylaxis of fungal infections in patients with acute leukemia. Results of a randomized placebo-controlled, double-blind, multicenter trial. Ann Intern Med 1993;118:495-503.

7. Cornely OA, Maertens J, Winston DJ, Perfect J, Ullmann AJ, Walsh TJ, et al. Posaconazole vs. fluconazole or itraconazole prophylaxis in patients with neutropenia. N Engl J Med 2007;356:348-59.

8. Meunier F, Gaya H, Calandra T, Glauser M, Klastersky J, Sylvester R. Empiric antifungal therapy in febrile granulocytopenic patients. EORTC International Antimicrobial Therapy Cooperative Group. Am J Med 1989;86:668-72.

9. Lin SJ, Schranz J, Teutsch SM. Aspergillosis case-fatality rate: Systematic review of the literature. Clin Infect Dis 2001;32:358-66.

10. Caggiano V, Weiss RV, Rickert TS, Linde-Zwirble WT. Incidence, cost, and mortality of neutropenia hospitalization associated with chemotherapy. Cancer 2005;103:1916-24

11. van Gool R. The cost of treating systemic fungal infections. Drugs 2001;61 Suppl 1:49-56.

12. De Pauw BE, Donnelly JP. Prophylaxis and aspergillosis--has the principle been proven? N Engl J Med 2007;356:409-11.
13. Sipsas NV, Bodey GP, Kontoyiannis DP. Perspectives for the management of febrile neutropenic patients with cancer in the $21^{\text {st }}$ century. Cancer 2005;103:1103-13.

14. Pizzo PA, Robichaud KJ, Gill FA, Witebsky FG. Empiric antibiotic and antifungal therapy for cancer patients with prolonged fever and granulocytopenia. Am J Med 1982;72:101-11.

15. Nucci M, Marr KA. Emerging fungal diseases. Clin Infect Dis 2005;41:521-6.

16. Chamilos G, Marom EM, Lewis RE, Lionakis MS, Kontoyiannis DP Predictors of pulmonary zygomycosis versus invasive pulmonary aspergillosis in patients with cancer. Clin Infect Dis 2005;41:60-6.

17. Lass-Florl C. The changing face of epidemiology of invasive fungal disease in Europe. Mycoses 2009;52:197-205.

18. Tortorano AM, Kibbler C, Peman J, Bernhardt H, Klingspor L, Grillot R. Candidaemia in Europe: Epidemiology and resistance. Int J Antimicrob Agents 2006;27:359-66.

19. Pfaller MA, Diekema DJ. Epidemiology of invasive candidiasis: A persistent public health problem. Clin Microbiol Rev 2007;20:133-63

20. Pfaller MA, Diekema DJ. Rare and emerging opportunistic fungal pathogens: Concern for resistance beyond Candida albicans and Aspergillus fumigatus. J Clin Microbiol 2004;42:4419-31.

21. Kami M, Machida U, Okuzumi K, Matsumura T, Mori Si S, Hori A, et al. Effect of fluconazole prophylaxis on fungal blood cultures: An autopsy-based study involving 720 patients with haematological malignancy. Br J Haematol 2002;117:40-6.

22. Pagano L, Offidani M, Fianchi L, Nosari A, Candoni A, Piccardi M, et al. Mucormycosis in hematologic patients. Haematologica 2004;89:207-14

23. Maertens J, Theunissen K, Verhoef G, Verschakelen J, Lagrou K, Verbeken E, et al. Galactomannan and computed tomography-based preemptive antifungal therapy in neutropenic patients at high risk for invasive fungal infection: A prospective feasibility study. Clin Infect Dis 2005;41:1242-50.

24. Cordonnier C, Pautas C, Maury S, Vekhoff A, Farhat H, Suarez F, et al. Empirical versus preemptive antifungal therapy for high-risk, febrile, neutropenic patients: A randomized, controlled trial. Clin Infect Dis 2009;48:1042-51.

25. Klastersky J, Paesmans M. Antifungal therapy in febrile neutropenic patients: Review of treatment choices and strategies for aspergillar infection. Support Care Cancer 2007;15:137-41.

26. Wingard JR. New approaches to invasive fungal infections in acute leukemia and hematopoietic stem cell transplant patients. Best Pract Res Clin Haematol 2007;20:99-107.

27. Maertens J. Evaluating prophylaxis of invasive fungal infections in patients with haematologic malignancies. Eur J Haematol 2007;78:275-82.

28. Leather HL, Wingard JR. New strategies of antifungal therapy in hematopoietic stem cell transplant recipients and patients with hematological malignancies. Blood Rev 2006;20:267-87.

29. Herbrecht R, Denning DW, Patterson TF, Bennett JE, Greene RE, Oestmann JW, et al. Voriconazole versus amphotericin B for primary therapy of invasive aspergillosis; Invasive Fungal Infections Group of the European Organisation for Research and Treatment of Cancer and the Global Aspergillus Study Group. N Eng1 J Med 2002;347:408-15.

30. Walsh TJ, Anaissie EJ, Denning DW, Herbrecht R, Kontoyiannis DP, 
Marr KA, et al. Treatment of aspergillosis: Clinical practice guidelines of the Infectious Diseases Society of America. Clin Infect Dis 2008;46:327-60.

31. Grimwade D, Walker H, Oliver F, Wheatley K, Harrison C, Harrison $\mathrm{G}$, et al. The importance of diagnostic cytogenetics on outcome in AML: Analysis of 1,612 patients entered into the MRC AML 10 trial. The Medical Research Council Adult and Children's Leukaemia Working Parties. Blood 1998;92:2322-33.

32. De Pauw B, Walsh TJ, Donnelly JP, Stevens DA, Edwards JE, Calandra T, et al. Revised definitions of invasive fungal disease from the European Organization for Research and Treatment of Cancer/Invasive Fungal Infections Cooperative Group and the National Institute of Allergy and Infectious Diseases Mycoses Study Group (EORTC/MSG) Consensus Group. Clin Infect Dis 2008;46:1813-21.

33. Maertens JA, Klont R, Masson C, Theunissen K, Meersseman W, Lagrou K, et al. Optimization of the cutoff value for the Aspergillus double-sandwich enzyme immunoassay. Clin Infect Dis 2007;44:1329-36.

34. Fenina A, Le Garrec MA, Koubi M. Les comptes nationaux de la santé en 2009. Drees 2010;736.

35. Robenshtok E, Gafter-Gvili A, Goldberg E, Weinberger M, Yeshurun M, Leibovici L, et al. Antifungal prophylaxis in cancer patients after chemotherapy or hematopoietic stem-cell transplantation: Systematic review and meta-analysis. J Clin Oncol 2007;25:5471-89.

36. Maertens J, Maertens V, Theunissen K, Meersseman W, Meersseman P, Meers S, et al. Bronchoalveolar lavage fluid galactomannan for the diagnosis of invasive pulmonary aspergillosis in patients with hematologic diseases. Clin Infect Dis 2009;49:1688-93.

37. Meersseman W, Lagrou K, Maertens J, Wilmer A, Hermans G, Vanderschueren S, et al. Galactomannan in bronchoalveolar lavage fluid: A tool for diagnosing aspergillosis in intensive care unit patients. Am J Respir Crit Care Med 2008;177:27-34.

38. Harrison E, Stalhberger T, Whelan R, Sugrue M, Wingard JR, Alexander BD, et al. Aspergillus DNA contamination in blood collection tubes. Diagn Microbiol Infect Dis 2010;67:392-4.

39. Florent M, Katsahian S, Vekhoff A, Levy V, Rio B, Marie JP, et al. Prospective evaluation of a polymerase chain reaction-ELISA targeted to Aspergillus fumigatus and Aspergillus flavus for the early diagnosis of invasive aspergillosis in patients with hematological malignancies. J Infect Dis 2006;193:741-7.

40. Klingspor L, Loeffler J. Aspergillus PCR formidable challenges and progress. Med Mycol 2009;47 Suppl 1:S241-7.

41. White PL, Bretagne S, Klingspor L, Melchers WJ, McCulloch E, Schulz B, et al. Aspergillus PCR: One step closer to standardization. J Clin Microbiol 2010;48:1231-40.

42. White PL, Perry MD, Loeffler J, Melchers W, Klingspor L, Bretagne S, et al. Critical stages of extracting DNA from Aspergillus fumigatus in whole-blood specimens. J Clin Microbiol 2010;48:3753-5.

43. Senn L, Robinson JO, Schmidt S, Knaup M, Asahi N, Satomura S, et al. 1,3-Beta-D-glucan antigenemia for early diagnosis of invasive fungal infections in neutropenic patients with acute leukemia. Clin Infect Dis 2008;46:878-85.

44. Krishna G, Martinho M, Chandrasekar P, Ullmann AJ, Patino H. Pharmacokinetics of oral posaconazole in allogeneic hematopoietic stem cell transplant recipients with graft-versus-host disease. Pharmacotherapy 2007;27:1627-36.

45. Courtney R, Wexler D, Radwanski E, Lim J, Laughlin M. Effect of food on the relative bioavailability of two oral formulations of posaconazole in healthy adults. Br J Clin Pharmacol 2004;57:218-22.

46. Andes D, Pascual A, Marchetti O. Antifungal therapeutic drug monitoring: Established and emerging indications. Antimicrob Agents Chemother 2009;53:24-34.

47. Stam WB, O'Sullivan AK, Rijnders B, Lugtenburg E, Span LF, Janssen JJ, et al. Economic evaluation of posaconazole vs. standard azole prophylaxis in high risk neutropenic patients in the Netherlands. Eur J Haematol 2008;81:467-74.

48. Michallet M, Benet T, Kraghel S, Sobh M, El Hamri M, Cannas G, et al. Aspergillose invasive; un nouveau facteur de risque déterminant sur la survie à cours et long termes des patients atteints de LAM; Abstract 07-37. Hématologie 2010;16:138.

49. Mann PA, McNicholas PM, Chau AS, Patel R, Mendrick C, Ullmann AJ, et al. Impact of antifungal prophylaxis on colonization and azole susceptibility of Candida species. Antimicrob Agents Chemother 2009;53:5026-34.

50. Munoz P, Bouza E, Cuenca-Estrella M, Eiros JM, Perez MJ, Sanchez-Somolinos M, et al. Saccharomyces cerevisiae fungemia: An emerging infectious disease. Clin Infect Dis 2005;40:1625-34.

51. Cornely OA, Maertens J, Winston DJ, Perfect J, Ullmann AJ, Walsh TJ, et al. Posaconazole vs. Fluconazole or Itraconazole Prophylaxis in Patients with Neutropenia. N Engl J Med 2007;356:348-59.

52. Rotstein C, Bow EJ, Laverdiere M, Ioannou S, Carr D, Moghaddam N. Randomized placebo-controlled trial of fluconazole prophylaxis for neutropenic cancer patients: Benefit based on purpose and intensity of cytotoxic therapy. the canadian fluconazole prophylaxis Study Group. Clin Infect Dis 1999;28:331-40.

53. Winston DJ, Chandrasekar PH, Lazarus HM, Goodman JL, Silber JL, Horowitz H, et al. Fluconazole prophylaxis of fungal infections in patients with acute leukemia. Results of a randomized placebo-controlled, double-blind, multicenter trial. Ann Intern Med 1993;118:495-503. 